\title{
Modeling the Heat Scheme of the Combined Heat and Power Plants Using
} the Software Product "Boiler Designer"

\author{
Konstantin A. Shtym, \\ Yuriy B. Goncharenko*, Tatyana A. Soloveva, \\ Dmitriy R. Bibikov and Pavel V. Vasilyev \\ Far Eastern Federal University \\ Vladivostok, Russian Federation
}

Received 28.09.2020, received in revised form 03.02.2021, accepted 17.02.2021

\begin{abstract}
This article describes the rationale for the development of a mathematical model of the thermal scheme of Vladivostok thermal power plant. Four types of turbines are installed at this plant, boiler units operate on coal and natural gas. This makes it difficult to effective load distribution between the turbine units. Application of simplified dependencies, built on the basis of the reporting data, allows to analyse the correctness of the load distribution between the units. The article provides an example of comparing the actual parameters of the plant and calculating based on the simplified characteristics of turbines. This example showing the loss of fuel equivalent from non-optimal load distribution. However, the use of such simplified characteristics has several shortcomings. These shortcomings do not allow using this as a universal method. There is a need to create a full-fledged mathematical model of thermal power plants. The model is developing on the basis of the Boiler Designer software package. The program has a modular structure and allows you to create mathematical models of each unit of equipment, and then, through the purpose of connections, assemble the thermal scheme of the station. This approach is actual for cross-linked heat and power plants, since it allows us to evaluate the efficiency of thermal scheme connections, and not just the operation of the equipment itself. The article provides a simplified model of the station, its advantages and disadvantages.
\end{abstract}

Keywords: model, turbine, boiler, boiler designer, power generation, heat supply, fuel equivalent, efficiency.

Citation: Shtym K.A., Goncharenkoi Yu.B., Soloveva T.A., Bibikov D.R., Vasilyev P.V. Modeling the heat scheme of the combined heat and power plants using the software product «Boiler Designer», J. Sib. Fed. Univ. Eng. \& Technol., 2021, 14(1), 130-139. DOI: 10.17516/1999-494X-0293

(C) Siberian Federal University. All rights reserved

This work is licensed under a Creative Commons Attribution-Non Commercial 4.0 International License (CC BY-NC 4.0).

* Corresponding author E-mail address: goncharenko.yub@dvfu.ru 


\title{
Моделирование тепловой схемы станции \\ с использованием программного продукта \\ «Boiler Designer»
}

\author{
К.А. Штым, Ю. Б. Гончаренко, \\ Т. А. Соловьёва, Д. Р. Бибиков, П. В. Васильев \\ Дальневосточнылй федеральнылй университет \\ Российская Федерация, Владивосток
}

\begin{abstract}
Аннотация. В данной статье приводятся обоснования для разработки математической модели тепловой схемы владивостокской ТЭЦ-2. На данной ТЭЦ установлено четыре типа турбин, котлоагрегаты работают на угле и природном газе. Это делает сложным процесс эффективного распределения нагрузки между турбоагрегатами. Применение упрощенных зависимостей, построенных на основе отчетных данных, позволяют проанализировать правильность распределения нагрузки между агрегатами. В статье выполнен пример сравнения фактических показателей работы ТЭЦ и расчета на основе предложенных упрощенных характеристик турбин, показаны потери условного топлива от неоптимального распределения нагрузки. Однако применение таких упрощенных характеристик имеет ряд недостатков. Эти недостатки не позволяют использовать данный подход как универсальный метод. С учетом вышесказанного вытекает необходимость создания полноценной математической модели ТЭЦ. В качестве основы для разработки модели применяется программный комплекс «Boiler Designer». Программа имеет модульную структуру и позволяет создавать математические модели каждой единицы оборудования, а затем через назначение связей собирать тепловую схему станции в целом. Данный подход актуален для ТЭЦ с поперечными связями, поскольку позволяет оценивать эффективность не только работы самого оборудования но и схемы его соединения. В статье приведена упрощенная модель станции, ее достоинства и недостатки.
\end{abstract}

Ключевые слова: модель, турбина, котлоагрегат, выработка электроэнергии, отпуск теплоты, условное топливо, коэффициент полезного действия.

Цитирование: Штым, К.А. Моделирование тепловой схемы станции с использованием программного продукта «Воiler Designer» / К. А. Штым, Ю. Б. Гончаренко, Т. А. Соловьёва, Д. Р. Бибиков, П. В. Васильев // Журн. Сиб. федер. ун-та. Техника и технологии, 2021, 14(1). C. 130-139. DOI: 10.17516/1999-494X-0293

На данный момент времени приоритетным направлением энергетической политики России является рациональное использование и экономия энергии. В современных условиях рациональное использование энергетических ресурсов становится одним из определяющих факторов роста экономики и социального развития. Данный подход позволяет при одинаковых уровнях энергообеспечения направлять высвобождающиеся ресурсы на другие, экономически важные, цели.

Разработка и внедрение программ по рационализации использования энергетических ресурсов и определение потенциала энергосбережения с учетом условий функционирования основных технологических объектов основываются на анализе фактического состояния эффективности использования энергетических ресурсов. Такие данные получают в ходе комплексного энергетического обследования предприятий [1].

Объектом исследования является «Владивостокская ТЭЦ-2», филиал «Приморской генерации» АО «ДГК» (далее ВТЭЦ-2), основным видом деятельности которой является производство 
и отпуск тепловой и электрической энергии для г. Владивостока. ВТЭЦ-2 - основной источник по обеспечению производственным паром, тепловой и электрической энергией промышленных и бытовых потребителей города. Установленная электрическая мощность станции составляет 497 МВт, тепловая - 1051 Гкал/ч. На ТЭЦ установлены 14 паровых котлов марки БКЗ-210-140 и 6 паровых турбин. В 2003 г. из-за неудовлетворительного состояния паропроводов высокого давления и необходимости продления паркового ресурса ТЭЦ была переведена на работу при сниженных параметрах острого пара: $\mathrm{P}_{0}=125$ кгс $/ \mathrm{cm}^{2}, \mathrm{t}_{0}=545^{\circ} \mathrm{C}$ (проектные параметры:

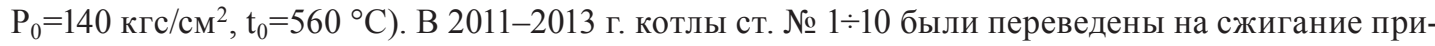
родного газа. Котлы ст. № 11 $\div 14$ работают на смеси бурых углей Павловского месторождения. В качестве резервного и растопочного топлива используется мазут М-100. На ТЭЦ были установлены паровые турбины: ст. № 1-4 Т-100/120-130-3, ст. № 5, 6 ПТ-80-130/13-2 шт. В связи с переводом на пониженные параметры турбины реконструированы. Турбоагрегат ст. № 1 реконструирован с целью перевода турбины на режим работы с противодавлением, доступ пара к ЦНД прекращен путем оглушения перепускных труб из ЦСД в ЦНД. Рабочие лопатки ступеней низкого давления срезаны по корневому диаметру для исключения вентилирования в ЦНД. На турбоагрегатах ст. № $2 \div 4$ произведена реконструкция с целью восстановления расхода свежего пара и тепловой нагрузки при пониженных параметрах пара, срезаны рабочие лопатки 2-й ступени и произведена рихтовка выходных кромок направляющих лопаток 3, 4, 5-й ступеней. Турбоагрегат ст. № 5 переведен на режим с противодавлением, доступ пара к трем последним ступеням ЦНД прекращен путем установки на сопловые решетки диафрагм этих ступеней специальных заглушек, рабочие лопатки этих ступеней срезаны по корневому диаметру для исключения потерь на вентилирование. Турбоагрегат ст. № 6 в связи с переводом на пониженные параметры имеет ограничение по пропуску пара, в результате чего снижена электрическая мощность. Основные характеристики турбин после реконструкции приведены в табл. 1.

Для оценки эффективности работы станции сотрудниками кафедры «Теплоэнергетика и теплотехника» ДВФУ было проведено энергетическое обследование ТЭЦ, некоторые его результаты представлены ниже. Одной из проблем станции является снижение объемов отпуска теплоты за счет перераспределения на другие источники (рис. 1). Это приводит к снижению выработки

Таблица 1. Основные характеристики турбин после реконструкции

Table 1. Basic characteristics of steam turbine units after reconstruction

\begin{tabular}{|c|c|c|c|c|c|c|}
\hline \multirow[b]{2}{*}{ № } & \multirow{2}{*}{$\begin{array}{c}\text { Тип, } \\
\text { модификация }\end{array}$} & \multirow{2}{*}{$\begin{array}{c}\text { Номинальная } \\
\text { мощность } \\
\text { (МВт) }\end{array}$} & \multirow{2}{*}{$\begin{array}{c}\text { Номинальная } \\
\text { тепловая нагрузка } \\
\text { (Гкал/ч) }\end{array}$} & \multicolumn{2}{|c|}{ Параметры свежего пара } & \multirow{2}{*}{$\begin{array}{c}\text { Наработка, ч } \\
\text { (на } 2017 \text { г.) }\end{array}$} \\
\hline & & & & $\begin{array}{c}\text { Температура } \\
\left({ }^{\circ} \mathrm{C}\right)\end{array}$ & $\begin{array}{c}\text { Давление } \\
\left(к г \mathrm{c} / \mathrm{cm}^{2}\right)\end{array}$ & \\
\hline 1 & P-80-115 & 80 & 178 & 540 & 115 & 260362 \\
\hline 2 & T-98-115 & 98 & 160 & 540 & 115 & 303351 \\
\hline 3 & T-105-115 & 105 & 168 & 540 & 115 & 299233 \\
\hline 4 & T-109-115 & 109 & 175 & 540 & 115 & 255507 \\
\hline 5 & ПР-50/60-115 & 50 & $143 / 47$ & 540 & 115 & 191104 \\
\hline 6 & ПТ-55-115 & 55 & $180 / 72$ & 540 & 115 & 211527 \\
\hline
\end{tabular}


электроэнергии по теплофикационному циклу, поскольку отпуск электроэнергии практически не изменяется. Выработка электроэнергии по конденсационному циклу увеличивается, что снижает экономичность работы ТЭЦ [2].

На рис. 2 приведен среднегодовой КПД котлов. Хорошо видно, что КПД котлов, работающих на угле (ст. № $11 \div 14)$, в среднем ниже примерно на 7-9 \%, чем у котлов, работающих на природном газе (ст. № $1 \div 10$ ).

Средний коэффициент избытка воздуха за топкой составляет: для котлов, работающих на угле, $\alpha_{\mathrm{r}}=1,6$; для котлов, работающих на газовом топливе, $\alpha_{\mathrm{T}}=1,3$. Температура уходящих газов для котлов, работающих на угле, выше на $25^{\circ} \mathrm{C}$. В результате происходит рост потерь тепла с уходящими газами. Для котлов, работающих на угле, дополнительно имеется потеря с механическим недожогом на уровне 3-4 \%. Можно отметить, что перевод котлов на сжигание газа положительно сказался на КПД котельного цеха.

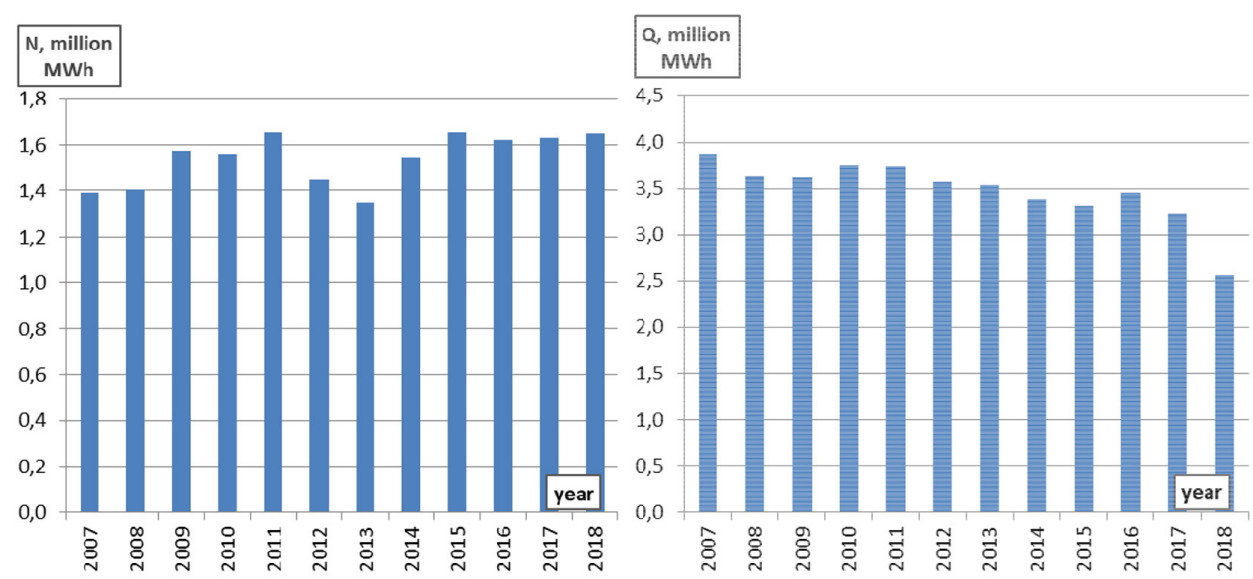

Рис. 1. Отпуск электроэнергии и теплоты

Fig. 1. Supplied electricity and heat energy

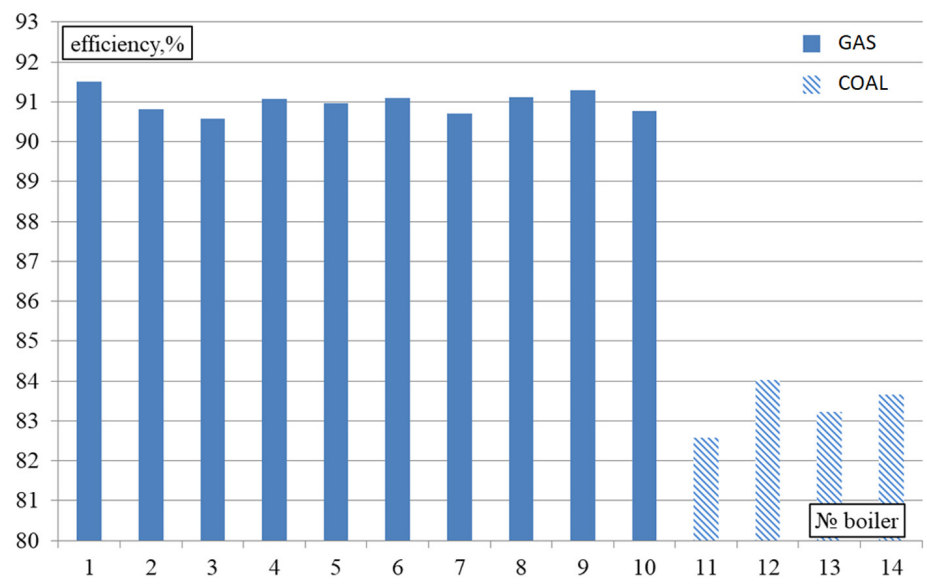

Рис. 2. КПД котлов

Fig. 2. Boiler efficiency 


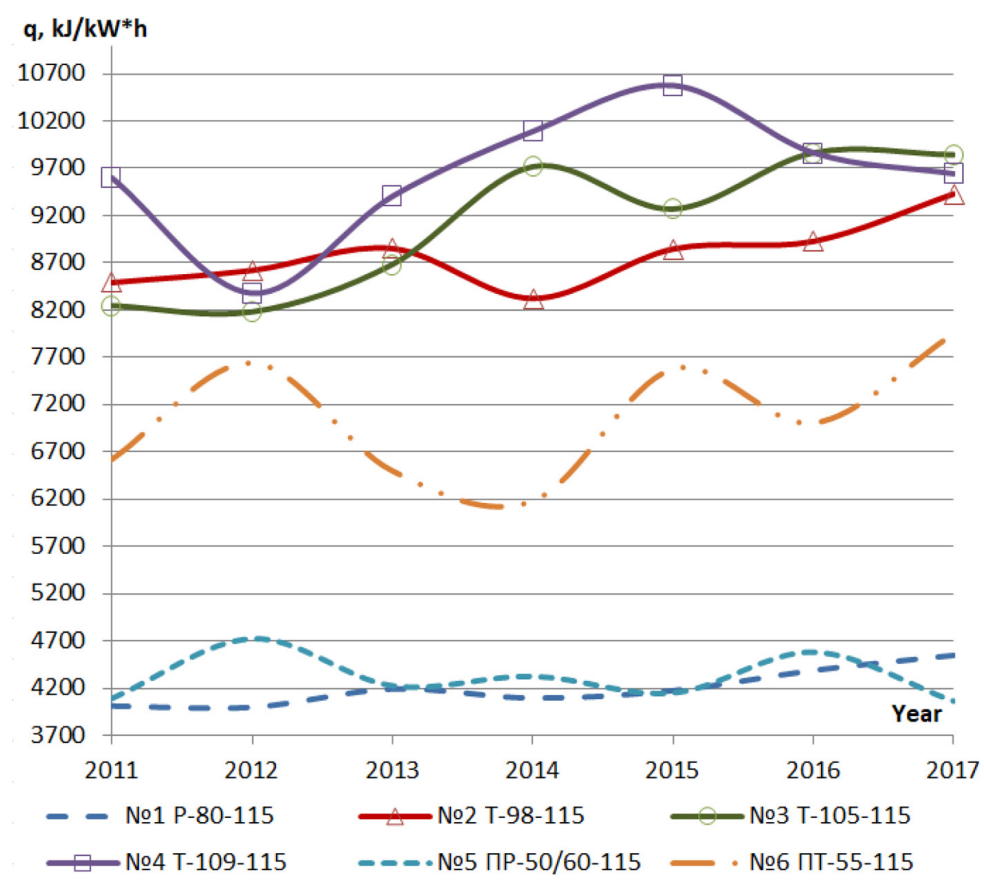

Рис. 3. Удельный расход теплоты на выработку электроэнергии

Fig. 3. Specific heat consumption for electricity generation

На рис. 3 представлена величина среднегодового удельного расхода теплоты на выработку электроэнергии для турбин разных типов. Данные графики построены на основе фактических показателей работы по отчетным формам электростанции. Хорошо видно, что для турбин ст. № 1,5 эта величина находится на уровне 4000-4700 кДж/кВт*ч, что примерно в три раза ниже, чем для остальных турбин. Это объясняется работой этих турбин в режиме противодавления [3], вся теплота, подведенная к турбине после прохождения проточной части, отдается потребителю, и потери теплоты в конденсаторе равны нулю.

Наличие большой разницы в показателях отдельных турбин делает актуальным вопрос о распределении электрической и тепловой нагрузки между турбинными агрегатами. С учетом имеющихся ограничений в работе турбин, таких как диапазон регулирования электрической и тепловой нагрузки, возможность работы в конденсационном режиме, задача по оптимальному распределению нагрузки становится не только актуальной, но и достаточно сложной.

\section{Метод статистической обработки отчетной документации}

В первом приближении эту задачу можно решить за счет статистического анализа показателей работы и построения по этим данным аппроксимирующих зависимостей, которые позволят представить удельный расход теплоты на выработку электроэнергии как зависимость от одного или нескольких параметров. Для турбин ВТЭЦ-2 были проанализированы данные форм отчетности 3-TEX и получены графические зависимости удельного расхода теплоты от текущей электрической и тепловой мощности. Пример такой зависимости приведен на рис. 4. Каждая точка на рисунке соответствует среднемесячному показателю, взятому из отчетной 


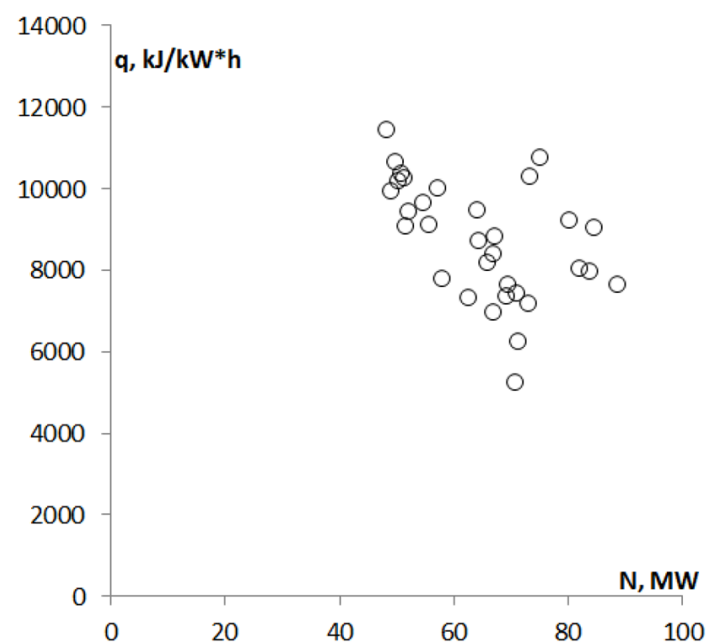

a) $q=f(N)$



b) $\mathrm{q}=\mathrm{f}(\mathrm{Q})$

Рис. 4

Fig. 4

документации. На рис. $4 a$ приведены данные по удельному расходу теплоты, построенные в зависимости от электрической мощности турбины. Можно отметить, что здесь не прослеживается однозначная зависимость в отличие от рис. $4 b$. Это позволяет сделать вывод, что для приближенного нахождения удельного расхода теплоты достаточно знать тепловую нагрузку турбоагрегата.

Полученные зависимости строились для каждой турбины, аппроксимировались, и получалось уравнение, позволяющее найти удельный расход теплоты в зависимости от тепловой нагрузки турбоагрегата.

Для турбоагрегата Р-80-115 ст. № 1:

$$
q^{\text {расчет }}=-174,9 * \ln \left(Q_{\text {то }}\right)+1786,6 .
$$

Для турбоагрегата Т-98-115 ст. № 2:

$$
q^{\text {расчет }}=-550,9 * \ln \left(Q_{\text {то }}\right)+4225,9 .
$$

Для турбоагрегата Т-105-115 ст. № 3:

$$
q^{\text {расчет }}=-497,8 * \ln \left(Q_{\text {то }}\right)+4018,8 .
$$

Для турбоагрегата Т-109-115 ст. № 4:

$$
q^{\text {расчет }}=-652,8 * \ln \left(Q_{\text {то }}\right)+4562,6 .
$$

Для турбоагрегата ПТ-55-115 ст. № 6:

$$
q^{\text {расчет }}=-851 * \ln \left(Q_{\text {то }}\right)+5694,5 .
$$

Для турбоагрегата ПР-50/60-115 ст. № 5 однозначной закономерности не прослеживается. 
При распределении нагрузки при помощи полученных зависимостей выводился из работы один турбоагрегат, а электрическая и тепловая нагрузка распределялись между оставшимися турбинами. Поскольку не удалось получить явную зависимость удельного расхода тепла от тепловой нагрузки для турбоагрегата ПР-50/60-115 ст. № 5, данный агрегат в распределении не участвовал, тепловая и электрическая нагрузка на данный агрегат оставалась без изменения. Турбина ПТ-55-115 ст. № 6 имеет производственный отбор, при отключении данной турбины нечем будет заместить пар с производственного отбора. Поэтому в распределении нагрузок данный турбоагрегат также не участвовал, неся неизменную электрическую и тепловую нагрузку.

Между оставшимися турбоагрегатами распределение было следующим: в первую очередь нагружался турбоагрегат Р-80-115 ст. № 1, оставшаяся нагрузка распределялась между двумя или тремя другими агрегатами равномерно, в зависимости от текущей тепловой и электрической мощности станции. Годовое снижение удельного расхода теплоты на выработку электроэнергии рассчитывали как средневзвешенное по выработке электроэнергии значение [4] по следующей формуле:

$$
\Delta q^{\text {год }}=\frac{\sum \Delta q_{i} \cdot \ni_{i}}{\sum Э_{i}}
$$

Результаты, рассчитанные для каждого месяца в течение года, и годовое снижение удельного расхода теплоты приведены в табл. 2.

Использование данного подхода позволяет получить экономию 9,4 \% за счет более рационального распределения нагрузки между турбоагрегатами.

Использование данного подхода легко реализовать на практике, однако имеется несколько ограничений и недостатков:

Таблица 2. Удельный расход теплоты до и после оптимизации

Table 2. Specific heat consumption before and after optimization

\begin{tabular}{|c|c|c|c|c|}
\hline Месяц & $\mathrm{q}^{\text {факт }}$, кДж/кВт*ч & $\mathrm{q}^{\text {расч }}$, кДж/кВт*ч & Э, тыс. кВт*ч & $\Delta \mathrm{q}, \%$ \\
\hline Январь & 6913 & 6327 & 224958 & 8,5 \\
\hline Февраль & 7432 & 6595 & 208671 & 11,3 \\
\hline Март & 7365 & 6812 & 197111 & 7,5 \\
\hline Апрель & 7189 & 7189 & 173838 & 0 \\
\hline Май & 9136 & 8537 & 159850 & 6,5 \\
\hline Июнь & 9077 & 8943 & 120371 & 1,5 \\
\hline Июль & 9969 & 8885 & 115097 & 10,9 \\
\hline Август & 11087 & 9793 & 96483 & 11,7 \\
\hline Сентябрь & 10978 & 9207 & 113074 & 16,1 \\
\hline Октябрь & 9044 & 7976 & 147214 & 11,8 \\
\hline Ноябрь & 7537 & 6779 & 187262 & 10 \\
\hline Декабрь & 7398 & 6289 & 215955 & 15 \\
\hline Всего & 8244 & 7474 & 1959885 & 9,4 \\
\hline
\end{tabular}


1. Для рассматриваемой станции удалось получить зависимости для пяти турбоагрегатов из шести установленных. Может сложиться такая ситуация, что после обработки статистической информации из отчетности ТЭС не будет прослеживаться явных зависимостей по большинству интересующего оборудования. В такой ситуации данный подход не применим.

2. Не учитываются оперативные переключения, изменяющие тепловую схему работы ТЭС. Например, при отключении ПВД удельный расход теплоты на выработку электроэнергии соответствующей турбины увеличится. Полученные зависимости усредняют характеристики оборудования и не учитывают текущий режим работы тепловой схемы. Это накладывает ограничение в использовании для оперативного управления работой ТЭС.

3. Для учета работы котельного оборудования необходимо строить соответствующие зависимости. Это усложняет общий алгоритм расчета. На ТЭС в настоящее время применяется методика расчета экономичности, в которой используются энергетические характеристики основного и вспомогательного оборудования. Однако данные расчеты в связи с большой трудоемкостью делаются в срезе одного месяца, что не дает возможности использовать их для оперативного управления.

\section{Создание модели в программе «Boiler Designer»}

Для устранения данных недостатков требуется создание модели ТЭС, которая будет учитывать характеристики работы основного и вспомогательного оборудования, а также позволит оперативно изменять тепловую схему ТЭС. Моделирование выполняется в программе «Boiler Designer», которая позволяет решать большой круг вопросов при моделировании теплоэнергетического оборудования $[5,6]$. Созданию модели ТЭС предшествует создание упрощенной модели станции. Исходные данные для моделирования станции в программе «Бойлер-дизайнер»:

1. Основные технические характеристики турбин.

2. Характеристика регенеративных отборов пара при номинальных параметрах пара и принципиальные тепловые схемы турбин.

3. Основные технические данные котлоагрегатов.

4. Упрощенная тепловая схема ВТЭЦ-2.

Разработанная модель (рис. 5) состоит из следующих элементов. Два «Имитатора котла», моделирующих работу 14 котлов. Один котел моделирует БКЗ-210-140Ф с 1 по 10 котел, работающие на газе. Второй моделирует котлы с 11 по 14, работающие на угле. Элемент «Регулятор расхода» воздействует на изменение расхода питательной воды в зависимости от расхода пара на турбоустановки.

Элемент КСН имитирует работу главного паропровода, в котором поддерживается заданное давление. Модели всех турбоустановок станции представлены отдельными блоками, каждый из которых можно раскрыть для подробного анализа или изменения схемы. Элемент «2 клапана» предназначен для регулирования подачи пара на каждую турбоустановку. Схема, имитирующая тепловые сети, в качестве источников тепла использует пар с отборов турбин или с РОУ. Элемент «РОУ», который моделирует работу РОУ 2,3; БРОУ 1,2; РРОУ 1,2. Элемент КСН, моделирующий коллектор 13 ата, являющийся источником теплоты для основных 


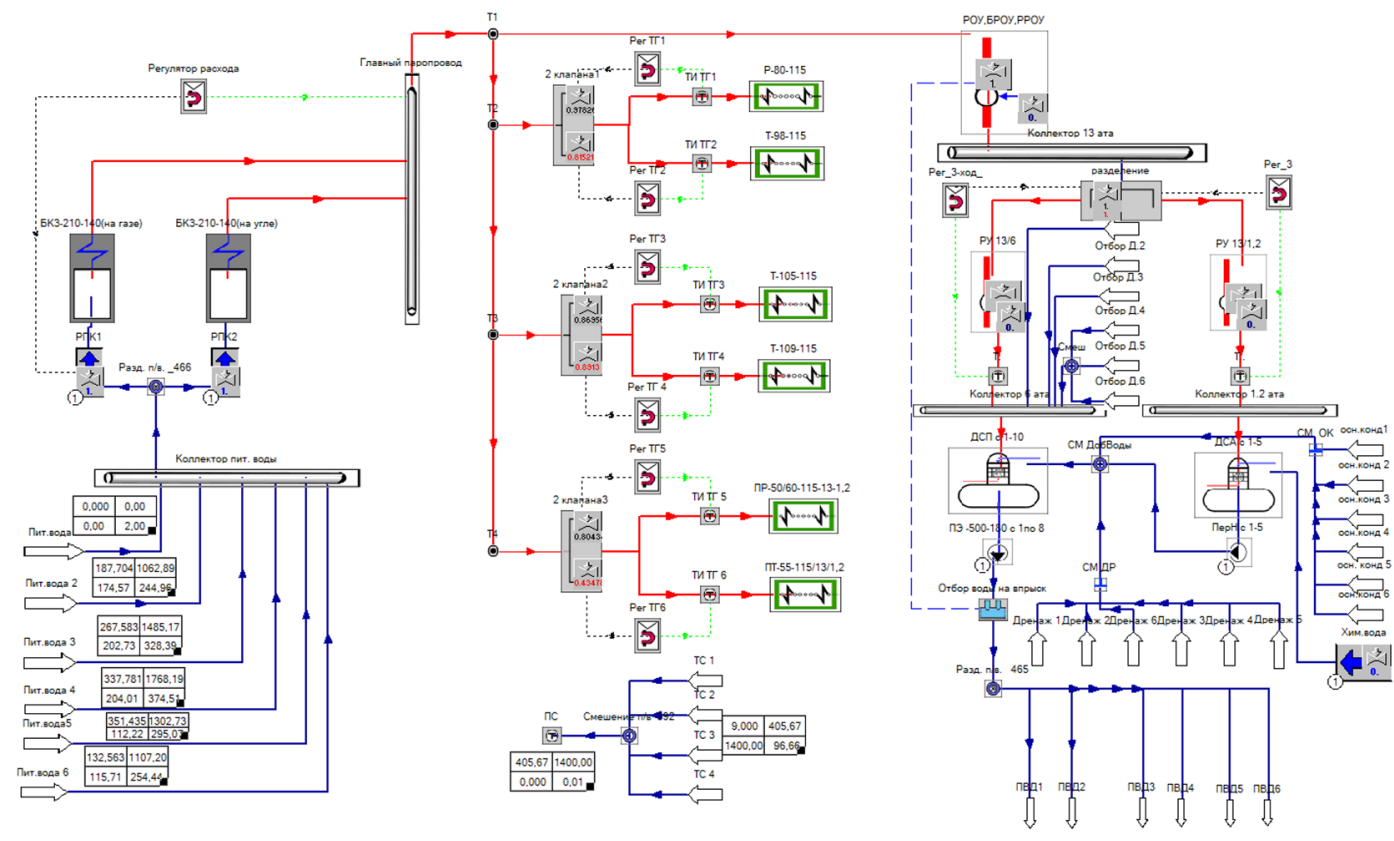

Рис. 5

Fig. 5

эжекторов, эжекторов отсоса турбин, коллектора группы греющего пара ДСП, пиковых бойлеров, внешнего теплового потребителя. Два элемента «РОУ», имитирующих РУ 13/6 и РУ 13/1,2. Первый элемент «Деаэратор» имитирует работу 10 деаэраторов повышенного давления ДСП. Второй имитирует работу 5 атмосферных деаэраторов ДСА-300 для подпитки котлов. Элемент «ПЭН» имитирует 8 питательных насосов ПЭ-500-180. Элемент «Отбор воды на впрыск «РОУ» имитирует впрыск воды на РОУ и БРОУ после третьей ступени ПЭНов.

На данной модели возможно производить перераспределение тепловой и электрической нагрузки между турбоагрегатами, варьировать отпуск теплоты как от отборов турбин, так и от РОУ; имея параллельную схему соединения ПВД, возможно изменять расход питательной воды по разным группам ПВД вплоть до их отключения по питательной воде, включать в работу как газовые, так и угольные котлы.

\section{Заключение}

В результате работы по созданию реальной модели ВТЭЦ-2 можно сделать следующие выводы:

1. Разнородное оборудование ВТЭЦ-2 требует тщательных расчетов при распределении нагрузки между турбоагрегатами; с учетом динамики изменения тепловой и электрической нагрузок задача по оптимальному распределению нагрузки становится не только актуальной, но и достаточно сложной. Лучшее решение данной задачи - математическая модель станции.

2. Создана упрощенная модель ВТЭЦ-2, приближенная к реальной станции.

3. При моделировании использовались параметры, взятые по инструкциям и из отчетов по тепловым испытаниям основного оборудования. 
4. Результаты моделирования находятся в плохом соответствии с фактическими показателями работы ТЭЦ.

5. Использованные при моделировании данных инструкций и отчетов по испытаниям являются недостаточными для полного описания работы оборудования, требуется выполнение дополнительных измерений для уточнения характеристик отдельных узлов и агрегатов.

6. Необходимо продолжение работы по усовершенствованию модели.

\section{Список литературы / References}

[1] Клюкин А.М., Кузнецов Н. М., Трибуналов С. Н. Энергетическое обследование -основа эффективного управления энергопотреблением. Труды Кольского научного центра РАН, 2015, 10(28), 16-23 [Klуикіn A. M., Kuznetsov N. M., Tribunalov S. N. Energy audit - the basis of effective energy management. Proceedings of the Kola Science Center RAS, 2015, 10 (28), 16-23 (in Russian)]

[2] Крайнов В.К., Салихов А.А. Повышение эффективности энергопроизводства. Анализ и пути реализации. Теплоэнергетика, 1997, 11, 26-30 [Kraynov V.K., Salihov A. A. Improving energy efficiency. Analysis and implementation. Thermal Engineering, 1997, 11, $26-30$ (in Russian)]

[3] Братченко Т.Н., Ильин Е. Т. Повышение экономичности ТЭЦ путем перевода турбоагрегата в режим противодавления. Радиоэлектроника, электротехника и энергетика: тезисы докладов Двадиать второй Международной научно-технической конференции студентов и аспирантов: в 3 m. Т. 3. Ядерная энергетика и теплофизика. 2016. 150 [Bratchenko T. N., Ilyin E. T. Improving the efficiency of CHPs by putting the turbine unit in backpressure mode. Radio electronics, electrical engineering and energy: abstracts of the Twenty-second International Scientific and Technical Conference of undergraduate and graduate students: in 3 vol. Vol. 3. Nuclear power and thermal physics. 2016. 150 (in Russian)]

[4] Каплан М.П. Тепловая эффективность энергоустановок различного типа с комбинированной выработкой тепловой и электрической энергии. Теплоэнергетика, 2000, 47(2), 116-120 [Kaplan M.P. The thermal efficiency of various types of combined heat-and-power generating plants. Thermal Engineering, 2000, 47(2), 116-120 (in Russian)]

[5] Волков С.В., Тишин К.П. Опыт использования «Boiler Designer» при проектировании теплоэлектроцентралей нефтехимического комплекса Труды Международной научнопрактической конференции «Boiler Designer-2014», 2014. 40-49 [Volkov S. V. Tishin K. P. Experie nce of using «Boiler Designer» in the design of combined heat and power plants of the petrochemical complex, Proceedings of the International Scientific and Practical Conference «Boiler Designer-2014», 2014. 40-49 (in Russian)]

[6] Berezinets P.A., Doverman G. I. Technology used to operate the 300-MW power unit topped with a GTE-110 gas turbine. Thermal engineering. 2010. 57(9), 729-734 